\title{
The Value of Women's Indigenous Knowledge in Food Processing and Preservation for Achieving Household Food Security in Rural Sudan
}

\author{
Fatma Osman Ibnouf \\ Development Studies and Research Institute (DSRI), University of Khartoum, \\ PO. box 321, Postal Code 11115, Khartoum, Sudan \\ E-mail: fatma_ibnouf@hotmail.com
}

Received: November 14, 2011

Accepted: November 30, 2011

Published: February 1, 2012

doi:10.5539/jfr.v1n1p238

URL: http://dx.doi.org/10.5539/jfr.v1n1p238

\begin{abstract}
Availability of food supply and access are crucial to achieve household food security. Using of indigenous knowledge in solving food shortage remains a powerful means of sustaining household food security. In rural Sudan women are often responsible for food processing and storage, collecting of water and firewood and for generating incomes for subsistence. The objective of this article is to shed light on women ability to manage available resources by using indigenous knowledge to secure food supplies for their household in rural Sudan. The paper argues that women have more roles and responsibilities in achieving household food security especially among the rural communities of Sudan, since it is woman who is responsible for food processing and preserving to increase its availability. Processing of vegetables, fruits, and milk, in times of abundance for times of scarcity using indigenous techniques such as drying or fermentation is exclusively the women's task in rural Sudan. Traditional/indigenous foods provide inexpensive, safe, nutritious foods throughout the whole year. These indigenous foods contribute to diversify the diet of rural people in normal times and are crucial to their survival during times of food shortage. Thus, these indigenous foods become basis of the survival of the rural community. Trial and error experiments contribute to develop many indigenous techniques and practices for processing and preserving foods at rural community level. Indigenous methods and solutions applied by women to sustain household food supplies are culturally acceptable, economically practicable, and more appropriate for the local environment and conditions than modern techniques and solutions suggested by scientific experts. The article gives a brief description of some indigenous foods from various rural areas of Sudan. Rural women have an important role to play in using and preserving this valuable indigenous knowledge. These local-level experts manage to achieve sustainable food security at household levels, with practical, efficient and economic solutions. Thus, one effective means to achieve household food security in rural Sudan is by learning from the women's indigenous knowledge and inherent capabilities. The value of women's indigenous knowledge needs to be better recognized and supported within policy.
\end{abstract}

KeyWords: Indigenous Knowledge, Women, Food Security, Rural Sudan

\section{Introduction}

The economy of rural Sudan has been centered on subsistence agricultural crop production and livestock rearing. Women represent the majority of the rural population (up to $70 \%$ according to censuses), especially where migration and male flee or death due to conflicts have left them as head of households. Women are extensively involved in agricultural activities which are the dominant livelihood feature of rural areas. Sudan's climate limits the production of food for only one rainy season (June to October). Food security at the household level refers to the ability of food providers to secure adequate food at all times to meet the dietary requirements and cultural preferences of their household members (Ibnouf, 2011). Indigenous knowledge represents valuable source of local solutions to the food insecurity in terms of accessibility by the rural population, particularly during seasonal food shortage or major stress periods such as droughts. As the managers of available live-based local resources and managers knowledgeable about local resources and environment, rural women are best placed to ensure sustainable food supplies and hence achievement of household food security. During seasonal food gaps, rural people are entirely dependent on the preserved foods as the only food source until the onset of harvest later in the 
year. Rural women possess an enormous amount of indigenous knowledge about food processing, preserving and other important survival skills. However, there is a concern that agricultural policy fall short of contributing to sustain food security, strengthening people-centred, respect the rights of all culture and wisdom of indigenous peoples and local communities.

In this paper, there is interchange in usage of the terms traditional and indigenous knowledge. Indigenous knowledge is knowledge that is unique to a given culture or society (Grenier, 1998). For the purpose of this paper indigenous knowledge includes local knowledge, skills known, and practiced in food processing, preservation, and storage activities which rural women derived from their direct interaction with the local environment. Such indigenous knowledge and its associated skills and practices are developed over ages, and passed down through the generations and became entrenched in people's cultures. New knowledge is regularly added to women's indigenous knowledge through innovation and through transfer of external knowledge to adapt to the changeable conditions. The indigenous foods produced through the use of these traditional methods and practices are sustainable means for achieving household food security in rural Sudan. The potential for indigenous knowledge to contribute to the achievement of household food security is tremendous. Indigenous knowledge is a resource widely ignored by development planners and policymakers. Hence, the paper objects to highlight how sustainable food security can be achieved in the vagaries climate situation of rural Sudan.

The methodology of this article depends on a survey of literature review and extensive use of practical examples to provide a comprehensive overview of indigenous knowledge used by rural women in processing and preserving of food in rural Sudan for household survival. In this context, the researcher utilized the data gathered through a number of her field studies throughout rural Sudan about the extent and nature of rural women's roles in food production and household food security. Direct observations of women engaged in food processing and preservation and grains storage activities. Most of indigenous food processing and preparation methods are well known to the researcher who is sometimes involved directly or indirectly in these food activities. Information was also obtained from documentary sources and relevant supportive literature such as books, journals, articles related to this study particularly a series of articles published by Prof. Hamid Dirar.

There has been little in the way of research that examines the contribution of indigenous knowledge to sustain household food supplies in rural Sudan. These knowledge gaps may sharply reduce the chances of achieving success in food security programs in the adversely affected region by environmental uncertainties, socio-economic problems, and conflicts. The use of the indigenous technique and practices in processing and preserving food products is also largely limited by lack of their documentations. A lot can also be learned from rural women's existing indigenous knowledge and its associated methods and practices for processing and preservation food products. More recognition of the role of indigenous knowledge in achieving household food security will give rural women a sense of the value and importance of traditional resources. These may assist to build resilience food security strategy for rural Sudan. The efficiency of the national food security policies can be judged by their ability to ensure food accessibility by the entire population in all regions of the Sudan, particularly the vulnerable population in rural areas.

\section{Background to Rural Sudan}

A clear understanding of the role of indigenous knowledge in the food security in rural Sudan entails a brief description of rural Sudan. Sudan is considered a very rich and diverse in land potential but equally so with ecological risks (Abdelgalil \& Cohen, 2001). Rural Sudan is already showing visible climate changes and further climate change is envisaged. Sudan is the single most arid county in Africa, thirty-one per cent of the territory is hyper-arid, and $63 \%$ are drylands susceptible to desertification and where $82 \%$ of the populations live (Ayoub, 1998). Most rural Sudan, like the rest of Africa's semi-arid and arid zone, suffered from the increasing frequency and severity of drought from the 1980s to date. The agricultural production in most Sudan and in turn food security depends upon the natural resources base. An observable danger is degradation of the natural resource base (the livelihood-based resources) and an increase in desertification. Despite technological advances such as improved crop varieties and irrigation systems, weather and climate are still key factors in agricultural productivity (Parry, et al. 1999). It follows, then, that the food security in rural areas is usually affected by the environment and natural resources. Most of the agriculture farming systems in rural Sudan is rain-fed, approximately 90 percent of the Sudan's cultivated areas depend exclusively on rainfall and the traditional rain-fed sector supports $70 \%$ of rural population (Federal Ministry of Environment and Physical Development 2003 , p. 40-41). Crop production is thus highly vulnerable to the climate hazards. Thus climate threatens the agro-pastoral and pastoral livelihood systems of arid and semi-arid rural people in several ways. The rural Sudan had experienced and is expected to experience marked reductions in agricultural productivity in the future as a result of recurrent droughts, desertification and other environmental hazards. The consequence of armed war and 
tribal conflicts in western Sudan region has also significantly impacted the country food security. A massive destruction of the natural resources has resulted as a direct consequence of these tribal conflicts and wars. Drought and civil conflicts led to increase the rural-urban migration, particularly of males from the subsistence farms to the urban areas.

In general, rural people are small-scale farmers and herders in the traditional rain-fed farming and livestock sectors. They usually practice subsistence agriculture, and their livelihoods are based on crop cultivation, herding and fishing, where available. Smallholder farmers are hindered by the limited size of their landholdings and low rates of productivity. Due to the lack of rainfall and domestic water supplies, for most farmers the growing season is short and crop failures are frequent. People living in rural areas have been or continue to be affected by drought and conflict - particularly in Darfur and the south Kordofan. A study indicates that food shortage is quite common before the rainy season until the harvest when food stocks are low, as indicated by $88 \%$ of surveyed sample in rural areas of northern Kordofan state (Ibnouf, 2008). However, over generations rural women have learned how to cope with these seasonal shortages by developed and adopted traditional foods based on their indigenous knowledge.

Patterns of adaptation behavioural responses in relation to an environment and socio-economic crises vary greatly across variety of contexts. Although there are many traditional adaptations used in rural Sudan, as well in Africa, however the use of indigenous knowledge is considered by virtue of its effectiveness (Orindi \& Murray, 2005; Ibnouf, 2008). Traditional adaptation strategies based on indigenous knowledge have played vital role in the lives of the arid and semi-arid communities in virtually every part of Africa (ibid). The indigenous knowledge is a critical safety valve that has created and developed out of necessity. Indigenous knowledge represents a valuable cultural capital and a concrete resource. Most of rural people in Sudan depend on indigenous knowledge in agriculture operations as well as in solving food shortage (Ali, 1997; Ibnouf, 2008). Rural people use their own knowledge of indigenous foods and agriculture provides better prospects for long-term sustainability than imposing solutions from outside. Both men and women may develop mechanisms to reduce risks or reverse processes of the specific conditions that take place in their local environment. However, it is often the rural women who produce, manage and market most of the food for their families and societies, and who work directly with natural resources (FAO, 2003 cited in Mwangi \& Dohrn, 2008, p. 240). It has also been stressed that rural women play a major role in actions to safeguard the environment, and therewith their communities' livelihoods and survival (Dankelman, 2002). Through using of indigenous knowledge in food processing and preservation women in rural Sudan, more than men, are usually seeking to find effective ways to ensure sustainability of the household food security. The preparation and storage of fermented foods by women are strongly dictated by the ecology of a hostile environment of drought, desertification and recurrent food shortage (Dirar, 1994).

\subsection{Importance of indigenous knowledge as life saving resources in rural Sudan}

Based on the above background, there is a need to learn about and to pay due attention to indigenous knowledge base of the rural communities. The resources available on arid and semiarid rural Sudan are cultivable lands, natural vegetation, and domestic animals, in addition to people indigenous knowledge. The indigenous knowledge enable people in rural Sudan, as well in Africa, survive the stressful conditions. This collective knowledge is critical to the survival and future wellbeing of local communities, and especially, of indigenous peoples as they try to maintain their livelihoods under difficult environmental conditions (Parrotta \& Agnolett, 2007). Indigenous knowledge provides the basis for problem-solving strategies for household food security in rural Sudan. Due to recurrent drought as a consequence of declining of rainfall and increase of dry season role of indigenous knowledge in sustain household food supplies is expanding in rural survival in rural arid and semi-arid areas. According to Elsiddig (2006) indigenous knowledge aims at management of the natural environment and is used to adapt to the requirements of the local conditions, allowing survival of the people in the western Sudan. In sub-Saharan Africa in general people have also traditionally utilized indigenous knowledge and skills, most often locally developed and handed down in the course of centuries (Oniang'o, et al. 2004). In surveys conducted in rural western Sudan, 80.4 percent of those surveyed confirmed that indigenous processed and preserved food products represent essential sources of foods and this is not limited to times of food shortage (Ibnouf, 2008). Processing and preserving of food products are greatly increases the value of perishable food stuffs by making them available for longer periods of time (Osunbitan, et al. 2000).

The traditional life cycle of rural people is a continuous process of acquiring, experiencing, possessing and sharing of traditional knowledge. Rural women tend to look for the most cost effective alternatives sources of foods for household survival. Traditional food processing and preservation activities constitute a crucial body of indigenous knowledge handed down from one generation to another. Social networks have still played crucial 
roles in indigenous knowledge transmission. The rural women have their own network through which they constantly gather information about new indigenous varieties.

Women in rural Sudan possess substantial indigenous knowledge about food production, processing, and preserving. Indigenous knowledge is that embedded in women daily practices to secure food consumption for their household members. Dried and fermented foods together with the seeds and fruits that can be gathered from the wild have saved lives especially those of children in the past and in the present in times of shortage in Sudan (Dirar, 1993).

Through understanding of indigenous knowledge, there is potential for sustaining food security in an environment of climate change and socio-economic problems. Many studied revealed that the traditional knowledge developed by women of processed and preserved foodstuffs has played an important role in coping with periods of food scarcity and famine in rural Sudan (Ali, 1997; Elsiddig, 2006, Ibnouf, 2008). Locally available agricultural and animal raw materials as well as wild products were processed into food products at relatively low cost resulting in food with higher nutritive value compared to the raw materials, had better taste, were culturally appropriate and acceptable, and had a longer shelf-life (Ibnouf, 2011). This clearly illustrates that rural women are quite capable of undertaking their own informal experiments and may arrive at practical solutions not originally anticipated by scientists and extensionists.

\section{Indigenous Knowledge and Practices in Food Processing and Preservation}

Besides being ethnically diverse, Sudan is one of the wealthiest countries in Africa in terms of cultural diversity. Culture plays a fundamental role in people eating habits. The types of food eaten by people are also determined by foods availability, affordability and what people are accustomed to eating. So, indigenous foods are plentiful and varied in rural Sudan. The indigenous knowledge and its associated skills is the result of centuries of adaptation to difficult food shortage crises. Indigenous food processing and storage operations are predominantly managed by women in rural Sudan. Rural women have been and will continue to be the inventor and preserver of the indigenous food techniques.

Rural women are usually using a diversity of simple and traditional food processing techniques to make a variety of traditional food products. These traditional food processing techniques are simple and low-cost and aim at long storage of foods. The technologies are based on indigenous knowledge and are adaptable to the culture of the people and to the environment. These processing techniques help in preventing growth of the micro-organisms that cause foods to decay and foods can be kept at ambient temperatures for long periods. Most of indigenous food processing and preparation methods are well known to most households in rural and urban areas alike. However, rural women are continuously experimenting, adapting and modifying traditional methods and techniques and practices for processing and preserving foods. Most indigenous processing methods are applied to foods to achieve preservation.

\subsection{Indigenous food processing and preservation techniques}

Sun drying - dehydration - is the one of the indigenous methods of food processing and preservation. Sun-drying traditional technique is usually done in three main ways. One method is to immerse fresh products e.g. vegetables in salted boiling water for a few minutes and then dry them under the sun for about three days. These are then stored in a safe, dry place. This method is also used to dry edible insects such as locusts and caterpillars. Another method is to directly spread the food under the sun. Food crops like sorghum, pearl millet, beans and groundnuts are usually kept drying under the sun before storage in traditional underground store or pits (locally called matmorah - can be of different shape and size) to increase their shelf life. Other food is first salted if there is danger of decaying during the drying process, as is the case with meats and tomatoes and afterwards stored in dry place at room temperature. Dried-tomatoes are then soaked in warm water to be turned into tomatoes sauce. Meat from slain animal sheep, goats, cow, and camel is first cut in long pieces, salted, smeared with powdered coriander, and dried for about a week to give a product called "shermout". In rural areas of western Sudan women tend to dry the layer of fat around the stomach that is called locally miriss and can be stored for a year. The large intestine may be cleaned and stuffed with fat and hung to dry for days as a type of sausage. The clean small intestines may also first be sun dried together with strips of the lungs, heart, kidneys, and liver and then all pounded together and mixed with some potash and molded into a fist-sized ball and allowed to slowly ferment and dry, to give twini-digla (Dirar, 1993). Women are key innovators, developing new ways to secure food supplies. Women in the rural western Sudan have developed a new food source from watermelon (Citrullus lanatus) by drying and then grinding watermelon seeds and using these dried seeds to make a porridge (called locally bajbaji), dried watermelon seeds can be preserved for years (Ibnouf, 2011). 
Fermentation is one of the oldest methods of food processing to make naturally fermented and cultured foods worldwide. Fermented foods and beverages are estimated to make up approximately $1 / 3$ of the human diet (Van Hylckama Vlieg, et al. 2011). As the sun-dried food can be stored indefinitely without deterioration, the fermentation processes represent a food preservation technique particularly well suited to the climate and conditions of arid and semi-arid areas. Fermentation is an important food processing technology usually developed by women in most Africa and Asian countries. However, the Sudanese women are more innovative using their indigenous knowledge of food fermentation as basis for further experimentation. For instance, Sudanese women invented unique fermented products which are white and red abreh/hulu-mur, a non-alcoholic fermented sorghum refreshing soft drinks for Ramadan (the holy month of fasting). While red abreh/hulu-mur is made of fermented sorghum dough prepared with equal amounts of flours from malted and un-malted sorghum, the white abreh is made from un-malted fermented sorghum dough. In indigenous fermentation, the starter consists of small amount of previously fermented materials to accelerate the fermentation process. The raw materials from which fermented foods are prepared include the better-known products such as sorghum, pearl millet, milk, fish, and meat, wild plants and also a number of unorthodox raw materials are fermented, bones, hides, skins, hooves, gall bladder, fat, intestines, caterpillars, locusts, honey, and cow urine (Dirar, 1994). Fermentation enhances the nutritional quality of foods and contributes to food safety particularly under conditions where refrigeration or other foods processing facilities are not available (Motarjemi, 2002) such as in rural Sudan. Some indigenous preparations, involving food fermentation, are quite elaborate and may take up to two weeks to complete. For example in rural western Sudan, a favourite choice to the meat substitute is kawal. Kawal is derived from the two-week long fermentation of the pounded green leaves of the Cassia obtusifolia legume. In the same region, the oil seedcake remaining after oil extraction from sesame seed (Sesamum orientale) is fermented for a week to make another meat substitute, called locally sigda.

Combination of two or three indigenous food processing techniques is common practices, i.e. fermentation and drying (Kawal) or salting, fermentation, and drying "shermout", germination, fermentation and drying "abreh/hulu-mur", etc. Processing of some products by women entails a complicated multi-step process, especialy those involving double methods of fermentation and sun-drying, are rather complicated and may take up to two weeks to complete. Fermented products are usually stored for a long period regardless of the weather conditions.

In southern Sudan, duma (a type of alcoholic drink) is made by fermenting diluted honey. The duma-making process is unique to southern Sudan, it is very fast, taking less than 12 hours; organisms which tolerate heat are involved; and the key link in the process is a special starter culture called iyal-duma (seeds of duma) (Dirar, 1993). The starter is originally raised from the roots of certain trees through a painstaking enrichment technique; it is then made into a paste consisting of an aggregate of a capsulated bacterium and two kinds of yeast (ibid). If washed thoroughly with water and sun-dried after each use, iyal-duma can be kept for years without losing its capacity to immediately start up fermentation when diluted honey is added (ibid).

The most widespread indigenous dairy products of Sudan are roob, kush-kush cheese and mish (spiced traditional yoghurt) which are usually produced during the rainy season and can be stored for use for the whole year. To prepare roob, fresh milk is left overnight for the souring process with some previous roob usually added as starter to accelerate the fermentation process. Another method to prepare roob is by putting sour milk in a skin bag and that is then churned and shacked to produce butter and roob. During this process small quantities of cold water are added once in a while to speed up the butter production. The butter is then removed by hand to a separate pot and heated to give traditional gee called locally samin which can be stored for several months. The remaining sour milk after butter removal is roob. Another traditional fermented milk product is mish, made by inoculating fresh milk with a small quantity of soured roob then spices like black cumin, fenugreek, garlic and black pepper are added and allowed for lengthening fermentation. Mish can be preserved and consumed for long time after it has been made. Nomadic women in Sudan make a type of a grainy indigenous cheese called kush-kush. To make kush-kush, women put sour milk into a skin bag that is fastened to the saddle of a camel to allow sour milk to continue the souring process until the curd is separated from the whey, and then the curd is collected and sundried to give kush-kush and is usually eaten with sorghum porridge.

Indigenous fermented and dried products are used to prepare a variety of sauces and stews. Different indigenous dishes are made of fermented-dried meat or vegetables or sour milk, with onions, oil, tomato puree, salted and spiced and served with porridge or kisra. Animal fat and offal are incubated in clay pots and left to ferment until foul, then pounded to soft paste and used as such (boiled with beans, or okra, onions, spices to make a sauce). In some rural areas of Sudan thick strips of fat-bearing meat are hung on a rope indoors and left to go through 
fermentation and then allowed to dry slowly to make another type of shermout and is made into a stew that is eaten with acida (stiff porridge) or kisra (unleavened bread).

Fresh bones may be fermented in a number of ways, the large bones, with pieces of attached meat and tendons, may simply be thrown on a thatched roof to ferment slowly for weeks or even months to give the product called adum; the meshy ball bone endings of the ball and socket joints may be pounded fresh and fermented into a paste called doddery; the vertebrae of the backbone may be chopped into smaller pieces that are sun dried, pounded with stones, mixed with a little water and salt, molded into a ball, and allowed to ferment and dry to give kaidu-digla (Dirar, 1993).

Sour milk "roob" substitutes are made from oil-bearing seeds in a manner analogous to the use of soybeans to give dairy product analogs, roob-heb is made from the seeds of the watermelon and roob-fui is made from peanuts (Dirar, 1993). In either case the seeds are pounded into a paste that is allowed to undergo a souring fermentation, when mixed with water and turned into sauce the product has the color (off white) and taste (sour) of the sour milk sauce called muiah-roob (ibid). A related product is um-zummatah, obtained by the souring fermentation of watermelon juice (Dirar, 1993).

The traditional commonly practiced fish preservation techniques are produced by fermentation with salting and drying, fermentation and drying without salting or fermentation with salting but without drying. Fessiekh and maluha/terkeen are types of wet-salted fermented fishery products and they are common in northern Sudan. Some of other fish products include kejeik (hard fermented sun-dried fish) popular as food fish for people in southern Sudan, mindeshi (minced small fish paste, fermented, and may be dried later) used by the people of western Sudan. Most of fermented fish is usually made from the whole small fishes and stored in an airtight container or dry place and it is soaked in lukewarm water before being prepared into various types of delicious foods.

Collecting and processing wild foods such as fruits, nuts, caterpillars, and some birds is also an important way of acquiring food for people who lives in rural areas. In Sudan, processed and preserved wild food products help in some cases to ensure a year round food supply (Hamid, 2006). Kawal a strong-smelling product derived from a two-week long fermentation of the pounded green leaves of the wild legume Cassia obtusifolia and can be preserved and consumed years after they have been made. The collection and preservation of forest and wild food products such as Cassia obtusiflora and Sonchus spp. is exclusively women's responsibility. These wild products are freely available in rural Sudan and represent important alternative food source during food shortage and famine. During the famine in Bahr el Ghazal, Southern Sudan in 1998, wild foods contributed more than any other food sources, including relief food, in saving the lives of large numbers of famine victims because of its unique characteristics of being easily available and affordable by all (Guvele, et al. 2003).

Women are contributing to increase food safety for households by locally-made traditional pesticides. The traditional pesticides such as citrus lemon leaves and neem (Indian Lilac; Azadirachta indica) are usually used for controlling pests that damage vegetable plants or attack the stored food grains (Ibnouf, 2008).

\subsection{Examples of indigenous foods}

This paper pays a closer attention to special category of indigenous food products that are developed by women in rural Sudan. The traditional food products by using indigenous knowledge have been a matter of survival for people in rural Sudan. There are substantial different types of indigenous processed foods in Sudan, which prepared from a wide range of substrates.

Sorghum and pearl millet have been an important part of Sudan's food culture for most rural populations. A very common soft drink that is associated of Ramadan is a unique drink called red abreh or 'hulu- mur literally means sweet and sour'. This is a slightly sweetened, refreshing drink made of thin flakes of fermented malted and un-malted sorghum flour. Preparations for making it start a month before the coming of Ramadan. The half patch of sorghum grain is moistened with water and allowed to germinate for six days - the germinated grain called 'zereah' which subsequently sun-dried and grinded. The other half of un-germinated sorghum grain is milled into fine flour and cooked directly into slightly thinner porridge and then malt flour is added to the porridge while is still hot then the mixture dough is left to ferment naturally in a dry place at room temperature for 24 to 36 hours - note that no kind of starter is used. Nine grounded spices add to dough to improve flavor, such as ginger, cinnamon, cardamom, pepper in addition to the liquid additives e.g. extracts of red hibiscus and tamarind and also date. The resulting red-colored sweet-sour fermented dough is then diluted with water to consistency of batter. About $50 \mathrm{ml}$ of batter is spread on hot ceramic pan for baking. Finally baked-sheets are left to dry in the shade for two days. The dry flakes may be stored for more than two years and used when desired. The baked-sheets crumble into flakes that are dispersed in water and allowed to soak for about an hour and then 
strained before sweetening and served cold. It is refreshing drink usually used to quench thirst after a long day of fasting (see Figure 1). The flake remains, after soaking and straining, is usually used as an animal feed.

Another type of abreh is white abreh which is also nonalcoholic drink with a slightly sour taste. White abreh is made using white variety of sorghum flour which is mixed with water and subsequently are left to ferment for three to five days before straining to remove the bran, adding the spices, and baking like kisra into very thin flakes and then dried for few hours and can be stored for the whole year. It is sweetened to taste and drunk without prior straining, which is also usually served during Ramadan (see Figure 2). Unlike hulu-mur, no malting is involved and the product is not strained.

Kisra bread is prepared from sorghum or pearl millet flour or their mixtures (depending on the region and production area). The fermented dough is prepared traditionally by mixing a small amount of the previously fermented dough to the mixture of flour and water to act as a starter, and then the dough is left to ferment overnight. The fermented dough is then baked on a hot steel plate $\left(150-160^{\circ} \mathrm{C}\right)$ in a process known as 'aowasa' and is a unique Sudanese art (El-Tinay et al. 1985). Dry piece of palm leaf (like a thin ruler) is used to swiftly spread small amount of the fermented dough into a very thin layer using quick, smooth sideways movements. The kisra is ready in about 30-40 seconds and ready to be peeled off (see Figure 3). Acida preparation: amount of stiff sorghum dough or pearl millet or their mixtures (prepared in the same manner as in kisra fermentation) is added to the boiling water with continuous stirring. Stirring continues until the dough is well cooked to stiff porridge (see Figure 4). Both kisra and acida are usually used on the daily basis and can be served with stews/sauce or with water and condiments or just eaten on its own as a whole meal. The indigenous stew/sauces are very diverse and can be made from cooked dry okra, curdled milk, fermented meat or vegetables are usually poured over kisra or acida and it is eaten with fingers.

Fessiekh is a wet-salted fermented fish (usually stored in an airtight container) is used as staple food and is widely produced and consumed in northern Sudan. It is used in the preparation of a common traditional dish called also fessiekh. The main components of the fessiekh stew, beside salted fermented fish are dried onions, tomatoes sauce, spices and peanut butter and usually served with traditional thick, soft, medium-size pancake bread made of corn and called locally groasah (see Figure 5).

The essential role of indigenous foods in the life of people in rural Sudan is reflected in their daily use as the above traditional dishes showed. Rural women are usually depended on resource-household level to make these traditional forms of food. The indigenous foods are 'the way of life' of the people in rural areas, and are considered 'the food of survival'. Rural women manage their available resources over the course of a year to meet their household food needs and to bridge food gaps and to sustain household food supplies. Women's indigenous knowledge for making of traditional forms of food is usually playing a vital role in survival of household in normal times as well in crisis situations.

\section{The Nutritional Value of Various Indigenous Foods}

One of the most common causes for dietary deficiencies and food insecurity appears to be the decreasing diversity of traditional diets. The article discusses the effects of indigenous food processing methods on food products nutrients. Indigenous foods are an important contribution to balancing the diet. Using of indigenous knowledge in food processing and preservation e.g., fermenting and malting may contribute to increase of the nutritional potential. Indigenous processed food products contribute to promote nutrient content and diversity and hence improving health of rural populations.

Through the years rural women have used very effective indigenous methods and techniques of food preservation. The products can be preserved for years and thus such products can be regarded as survival and nutritional foods. In food processing and preservation the scientific knowledge of women is clearly demonstrated in identification of the variety, and in innovation of ways to preserve the food for a long time without loss of nutrition as well as taste. Indigenous foods have the nutritional equivalent of introduced vegetables and cereals and in some cases are superior to them. Processing techniques such as soaking, germination and fermentation have been found to reduce significantly the levels of phytates and tannins by exogenous and endogenous enzymes formed during processing (Nuha, et al. 2010). A number of studies confirmed the importance of fermentation as a simple technique for improving both the nutritional and functional properties of traditional staple food grains and animal products (see Belton \& Taylor, 2004). The beneficial effects associated with fermented foods include reduced loss of raw materials, reduced cooking time, improvement of protein quality and carbohydrate digestibility, increased shelf life and microbiological safety of a food and improved bioavailability of micronutrients, general improvement in the texture, taste, aroma and elimination of toxic and anti-nutritional factors (Iwuoha \& Eke, 1996; Mensah, 1997; Caplice \& Fitzgerald, 1999; Motarjemi, 2002). 
Cereals, legumes, and tubers that are used for the production of fermented foods may contain significant amounts of anti-nutritional or toxic components such as phytates, tannins, cyanogenic glycosides, oxalates, saponins, lectins, and inhibitors of enzymes such as alpha-amylase, trypsin, and chymotrypsin (Reddy \& Pierson, 1994). The latter authors state that these substances reduce the nutritional value of foods by interfering with the mineral bioavailability and digestibility of proteins and carbohydrates. In natural or pure mixed-culture fermentation of plant foods by yeasts, molds, and bacteria, anti-nutritional components (e.g. phytate in whole wheat breads) can be reduced by up to $50 \%$; toxic components, such as lectins in fermented foods made from beans, can be reduced up to $95 \%$ (ibid). Indigenous fermented milk products have been evaluated by a number of Sudanese scholars. The processing of roob and mish, using spices like black cumin, fenugreek, garlic and other known spices, those spices were proved to have significant effect as preservative (El-Zubeir, et al. 2005).

A considerable portion of the nutritional needs of rural people is usually meet through traditional fermented foods. Traditional fermented foods consist of a wide range of products sourced from cereals, fruits, legumes, meat, fish, milk and wild foods. These traditional fermented foods are of great importance because they provide and preserve vast quantities of nutritious foods in a wide diversity of flavors which improve the value of foods. In rural Sudan, particularly in Kordofan and Darfur regions of western Sudan popular substitutes for the meat are indigenous fermented foods kawal, sigd, and furundu. All these products are dried after fermentation in the form of hard, irregular, small balls and may be kept for years. Leaves of Cassia obtusifolia (Sicklepod), widely grown in western Sudan, are fermented and sundried to produce a traditional food product, called locally kawal. Kawal is produced by solid state fermentation of readily available plant material of little or no economic value Cassia obtusifolia which, though unpalatable and toxic in its natural state, contains protein rich in sulfur amino acids (Dirar, 1984). Fermentation was found to cause significant changes in Cassia obtusifolia leaves major nutrients; fat content increased from 3.50 to $4.50 \%$, protein content from 24.81 to $35.13 \%$, ash content from 13.67 to $18.00 \%$, and fiber content decreased from 13.04 to $12.90 \%$ (Dirar, 1984; Nuha, et al. 2010). The anti-nutritional factors (tannin, phytate and total poly-phenols) of the Cassia obtusifolia leaves were significantly $(\mathrm{P} \leq 0.05)$ decreased after fermentation and cooking (Nuha, et al. 2010). Furundu, a similar meat substitute, is prepared by cooking the seeds of hibiscus (Hibiscus sabdariffa) or red sorrel and then fermenting for more than a week. The results of the study conducted by Yagoub \& Mohammed (2008) indicate that furundu raised from the cooked hibiscus seed have considerable amounts of essential amino acids and minerals and the $\mathrm{HCl}$-extractability of minerals were improved by furundu preparation. The latter authors show that the protein content of the hibiscus seed was $32.28 \%$, fermentation of the cooked hibiscus seed (furundu) significantly ( $<<$ 0.05 ) increased the level of the protein to $33.03 \%$ (see Table 1 ).

In Sudan, sorghum and pearl millet are staple foods and form a major dietary component for a large part of the rural population. The diets of rural Sudan populations are basically traditional fermented cereals (sorghum and pearl millet) based. Fermenting sorghum and pearl millet preserve and give a sour flavor which is well-accepted and particularly enjoyed. The process upgrades the taste and nutritive value of these crops. It raises the levels and bio-availability of proteins, vitamins and minerals. The chemical characteristics of fermented dough and baked kisra (traditional flatbread) and acida (stiff porridge) have been examined by many Sudanese researchers (El-Tinay et al. 1985; Abdelgadir, et al. 2005). The chemical composition of sorghum and pearl millet before and after fermentation and the nutrient contents of the traditional fermented food items kisra and acida were shown in Table 2. The crude fiber and protein were reported to have been increased by fermentation.

In preparation of hulu-mur, germination of grains caused significant increases ( $\mathrm{p}<0.01)$ of zinc $(90 \%)$, lead $(65 \%)$ and molybdenum (58\%) (Mahgoub, et al. 1999). The latter authors pointed out that addition of spices to hulu-mur dough caused significant increases $(\mathrm{p}<0.01)$ of strontium $(80 \%)$, calcium $(60 \%)$ and iron $(35 \%)$. Baking of hulu-mur did not cause any significant loss $(\mathrm{p}<0.01)$ in the contents of minerals (ibid).

Fermentation also helps protecting food from harmful microorganisms and reduces the risk of pathogenic diarrhea, a leading cause of infant death in rural Sudan. Microbial analysis of the sorghum before and after fermentation revealed that coli-form bacteria ' $E$. coli' counts exceeded 2.400 unites per gram (cfu/g) in the raw sorghum flour but the counts were very low in the fermented dough (Yagoub, et al. 2009). Latter authors point-out that Salmonella detected in the different sorghum varieties disappeared in the fermented dough after 24 hours fermentation. This might be due to the reduction of $\mathrm{pH}$ and accumulation of organic acids in the fermented sorghum flour, to production of certain microbial byproducts which eliminated these pathogens (ibid).

\section{Lessons Learned from Women Indigenous Knowledge in Food Processing and Preservation}

This paper attempts to focus on women's roles in the household survival in rural Sudan by considering how their indigenous knowledge leads to sustain household food supplies. Women more than men are often generated a 
great deal of indigenous knowledge in terms of dealing with different situations. Indigenous knowledge and practices in food processing and preserving can be regarded as the optimum method of dealing with practical circumstances surrounding survival of households in rural Sudan. The lesson learnt from the analyses presented in this paper, however, is that the indigenous knowledge and practices are fundamental to the endurance of rural women as they struggling to achieve household food security in rural areas of Sudan. Rural women's active involvement in diversify of food sources and efforts to develop alternative sources for household food supplies constitutes an essential part of achieving household food security.

This review indicates that rural women are more likely than men to use available resources and skills to sustain the living and further improve the nutritional status of their family. The traditional knowledge methods using in processing and preserving food products are regularly modernized and adapted since it becomes part of rural livelihood systems. Efficient utilization of local resources and efforts play a key role in enhancing rural people capacity to adapt different climate and socio-economic stressful conditions.

Women in most rural Sudan offer a number of traditional food products that are favourable to the food supply, quality and safety. These food items contribute to improving food access and availability to meet household needs in undesirable climate and socio-economic conditions. Locally available agricultural, raw material is processed into food products at relatively low cost resulting in food with a higher nutritive value compared to the raw material, a better taste and a longer shelf-life (cf. Van de Sande, 1997). Given the importance of indigenous knowledge that is used for food processing and preservation, it may therefore play a critical role in ensuring food security for the rural Sudan. Thus it will ensure the availability and utilization of these indigenous food sources for resource-poor rural communities. Therefore, indigenous knowledge and practices in food processing and preservation provides some valuable lessons to policymakers. Although insufficient attention has been given to use of the indigenous knowledge to sustain household food supplies, however integrating the indigenous knowledge within the mainstream development intervention may facilitate the culturally acceptable and desirable practicing. Therefore, interventions agreeable by both local people and stakeholders can be identified since they will possibly more successfully than other interventions which may jeopardize the indigenous people living systems. When indigenous techniques are improved, dissemination is usually faster, more widespread and cheaper because it fits better into local environmental and socio-economic niches (Reijntjes, et al. 1994 cited in Van Dijk, 1997, p. 17).

The indigenous food processing technologies are infrequently documented, evaluated and/or incorporated in the modern food chain. The potential disappearance of most of indigenous knowledge could have a negative effect on rural people who have developed and make a living through them. Therefore, paying the needed attention to indigenous knowledge will contribute to promote the cultural dimension of rural development. Unfortunately, so far there are no development strategies that seek to encourage rural women to use the indigenous knowledge to achieve household food security.

\section{Concluding Remarks and Policy Recommendations}

In conclusion, this study argued that women in rural Sudan tend to use available locally resources effectively in achieving household food security, and since women are responsible for food processing and food preserving, they contribute more to household survival. This paper argues that women in rural Sudan employ a variety of methods based on indigenous knowledge in processing and preserving of agricultural and animal raw materials and wild food products to acquire alternative food sources and to relieve the stress of seasonal food scarcity particularly during shortage of rainfall or drought and thus achievement household food security. Based on the result of this study in rural Sudan, different indigenous techniques from fermentation to sun-drying are viewed as unique techniques to preserve foods for years. Although indigenous knowledge about foods is usually invisible in conventional economic analysis, however indigenous foods have been a matter of survival for people in rural Sudan. So, it is necessary to look at indigenous knowledge as a way of building the capacity of rural women and give them larger extent to utilize their potential, since their using of indigenous knowledge in food processing and preserving is a very practical mechanism. Therefore, instead of transferring alien approaches and plans, it seems meaningful, socially as well as technically, to upgrade indigenous knowledge for achieving rural food security.

Given the vital role that indigenous knowledge plays in securing household food supplies, the continued undervaluing such knowledge is prejudice to rural women and is inimical to development of rural areas. Therefore, the most critical need in rural areas is to foster women that can promote sound adaptive strategies in the context of sustainable rural development objectives. So, some policy recommendations are made as follow: 
Support of rural women's indigenous knowledge may contribute to achieve of household food security in rural areas as it does allow for a variety of options. Promote sustainable development that is culturally appropriate to traditional societies requires the enhancing of the indigenous knowledge which allow the survival and renewal of culture, and is important generator of innovation.

In the designing of food security strategies and policies, studying rural women's indigenous knowledge can be a rewarding experience. Only when policy makers in Sudan accurately understand rural peoples' indigenous knowledge and its socio-cultural values that support survival of these people under stressful conditions of food shortage can they enact policies that will realistically achieve sustainable food security.

Construct new food habit and change the ways of living are often undesirable by indigenous people. Include of indigenous knowledge in any programs construction assist to increase people confidence on themselves and their ability to have their own solutions for food insecurity problems. Incorporating of indigenous knowledge into food security intervention in any rural areas development programs can provide valuable input for alternative resources.

Considering the current environment obstacles and future threatens, conservation of indigenous knowledge should be closely evaluated, as it is often the result of long experiences. There is the risk that the erosion of this indigenous knowledge in favour of modern knowledge could leave many traditional rural communities with neither traditional nor modern preparations to combat food crises. Indigenous knowledge is usually orally transmitted and infrequently recorded. In Africa, AS WELL IN Sudan, indigenous knowledge is stored in peoples' memories and activities and is expressed in stories, proverbs, cultural values, beliefs, and local language (Grenier, 1998). One of the highest ranking priority activities should be the development of recording systems, to record the useful indigenous knowledge about food before they are completely lost.

There is a need for a systematic effort to inventory and analysis of the role of indigenous foods in alleviating food insecurity and understand its working in the context of rural communities.

Sustain household food supplies through traditional food that is based on women indigenous knowledge in rural Sudan could be enhanced and supported to function as food security national policy frameworks.

There is a need for developing agricultural and nutritional training programs which address ways of preserving indigenous knowledge for sustainable food security.

It is hope that this paper will encourage further, much needed interdisciplinary research on topics related to the potential future roles of indigenous knowledge that governed and guided indigenous foods practices, embedded deeply in the socioeconomic and cultural fabric of Sudan rural communities, in promoting more sustainable food security for people in this era of climate change. Further research into the nutritional values of the indigenous food may eventually enhance a change of attitude and the possible future propagation of those indigenous foods. The findings of such analysis should be disseminated through publications and extension workers to benefit the population at large. These will help in identifying and documenting what already exists. It is therefore important to have relevant studies undertaken and indigenous knowledge documented in order to help counter rural food insecurity.

\section{References}

A. A. Yagoub \& Mohammed, M. A. (2008). Fururndu, a Meat Substitute from Fermented Roselle (Hibiscus sabdariffa L.) Seed: Investigation on Amino Acids Composition, Protein Fractions, Minerals Content and HCl-Extractability and Microbial Growth. Pakistan Journal of Nutrition: 7, (2), 352-358. [Online] Available: http://www.pjbs.org/pjnonline/fin929.pdf

Abdelgadir, M. Abbas, M. Jarvi, A. Elbagir, M. Eltom, M. \& Berne C. (2005). Glycaemic and insulin responses of six traditional Sudanese carbohydrate-rich meals in subjects with Type 2 diabetes mellitus. Diabetic Medicine: 22, (2), 213-217. http://dx.doi.org/10.1111/j.1464-5491.2004.01385.x

Abdelgalil, E. A. \& Cohen, S. I. (2001). Policy Modelling of the Trade-off between Agricultural Development and Land Degradation-the Sudan Case. Journal of Policy Modelling: 23, (8), 847-874. http://dx.doi.org/10.1016/S0161-8938(01)00089-8

Ali, N. M. A. (1997). Women's Coping Strategies at Time of Food Crisis: A case study Of North Kordofan State (1985 - 1995). Unpublished M.Sc. Thesis, Faculty of Economics and Social Studies 1997, University of Khartoum, Khartoum.

Ayoub, A. T. (1998). Extent, severity and causative factors of land degradation in the Sudan. Journal of Arid Environments: 38, (3), 397-409. http://dx.doi.org/10.1006/jare.1997.0346 
Belton, P. S. \& Taylor, J. R. N. (2004). Sorghum and millets: protein sources for Africa. Trends in Food Science \& Technology: 15, 94-98. http://dx.doi.org/10.1016/j.tifs.2003.09.002

Caplice, E. \& Fitzgerald, G. F. (1999). Food fermentations: role of microorganisms in food production and preservation. International Journal of Food Microbiology: 50, (1-2), 131-149. http://dx.doi.org/10.1016/S0168-1605(99)00082-3

Dankelman, I. (2002). Climate change: learning from gender analysis and rural women's experiences of organizing for sustainable development. Gender \& Development: 10, (2), 21-29. [Online] Available: http:/grove.ufl.edu/ gender/Readings/ReadingsW9/ClimateChange.pdf

Dirar, H. A. (1984). Kawal, Meat Substitute from Fermented Cassia Obtusifolia Leaves. Economic Botany: 38, (3), 342-349. http://dx.doi.org/10.1007/BF02859013

Dirar, H. A. (1993). The Indigenous Fermented Foods of the Sudan: A Study in African Food and Nutrition. CAB International: Wallingford: Oxon, UK.

Dirar, H. A. (1994). Commentary: The fermented foods of the Sudan. Ecology of Food and Nutrition: 32, (3-4), 207-218. http://dx.doi.org/10.1080/03670244.1994.9991401

Elsiddig, E. A. (2006). The role of indigenous knowledge in the livelihood activities of rural communities in Sudan. Eighth International Conference on Dryland Development. 25-28 February 2006, Beijing. [Online] Available Abstract: http://www.icarda.org/Publications/8th-ICDD-AbstractsBook/Theme8.pdf

El-Tinay, A. H., El Mahdi, Z. M. \& El Soubki, A. (1985). Supplementation of fermented sorghum kisra bread with legume protein isolates. Journal of Food Technology: 20, (6), 679-687.

El-Zubeir, I. E. M. Abdalla, W. M. and El Owni, O. A. O. (2005). Chemical composition of fermented milk (roob and mish) in Sudan. Food Control: 16, (7), 633-637. http://dx.doi.org/10.1016/j.foodcont.2004.07.003

Federal Ministry of Environment and Physical Development, (2003). Sudan's First National Communications under the United Nations Framework Convention on Climate Change. Volume 1, Ministry of Environment and Physical Development, Higher Council for Environment and Natural Resources, Khartoum. United Nations Framework Convention on Climate Change. [Online] Available: http://unfccc.int/resource/docs/natc/sudnc1.pdf

Grenier, L. (1998). Working with indigenous knowledge: A Guide for Researchers. Published by the International Development Research Centre (IDRC), Ottawa. URI: http://hdl.handle.net/10625/16526

Guvele, C., Deng, L. B., Itto A., \& D'Silva, B. (2003). Food Security Analysis. Institute of Development Studies (IDS), University of Sussex, Brighton. Analysis was presented at the Rumbek Strategy Meeting.

Hamid, A. A. (2006). Dry-lands Forestry; a Means of Livelihood and Poverty Reduction for the Rural People in the Sudan. Conference Paper, Conference Organizers: The World Conservation Union (IUCN), United Nations Educational, Scientific and Cultural Organization (UNESCO) and UNESCO Chair of Desert Studies and Desertification Control, Yarmouk University, Amman. [Online] Available: http://www.iucn.org/themes/cem/documents/drylands/drylands_forestry_sudan_hamid2006.pdf

Ibnouf, F. O. (2011). Challenges and possibilities for achieving household food security in the Western Sudan region: the role of female farmers. Journal of Food Security, 3, (2), 215-231. http://dx.doi.org/10.1007/s12571-011-0118-3

Ibnouf, F. O. 2008, Role of Women in Providing and Improving Household Food Security in Rural Sudan. Unpublished PhD Thesis, University of Wales Swansea, Swansea, UK.

Iwuoha, C. I. \& Eke, O. S. (1996). Nigerian indigenous fermented foods: their traditional process operation, inherent problems, improvements and current status. Food Research International: 29, (5-6), 527-540. http://dx.doi.org/10.1016/0963-9969(95)00045-3

Mahgoub, S. E. O. Ahmed, B. M. Ahmed, M. M. O. \& El Agib, E. N. A. (1999). Effect of traditional Sudanese processing of kisra bread and hulu-mur drink on their thiamine, riboflavin and mineral contents. Food Chemistry: 67, (2), 129-133. http://dx.doi.org/10.1016/S0308-8146(99)00074-6

Mensah, P. 1997, Fermentation - the key to food safety assurance in Africa? Food Control: 8, (5-6), 271-278. http://dx.doi.org/10.1016/S0956-7135(97)00020-0

Motarjemi, Y. (2002). Impact of small scale Fermentation technology on food safety in developing countries. International Journal of Food Microbiology: $75, \quad$ (3), 213-229. http://dx.doi.org/10.1016/S0168-1605(01)00709-7 
Mwangi, E. \& Dohrn, S. (2008). Securing access to drylands resources for multiple users in Africa: A review of recent research. Land Use Policy: 25, (2), 240-248. http://dx.doi.org/10.1016/j.landusepol.2007.07.002

Nuha, M. O. Isam, A. M. A. \& Elfadil, E. B. (2010). Chemical composition, anti-nutrients and extractable minerals of Sicklepod (Cassia obtusifolia) leaves as influenced by fermentation and cooking. International Food Research Journal: 17, 775-785. [Online] Available: http://www.ifrj.upm.edu.my/17\%20(03)\%202010/IFRJ-2010-775-785\%20Elfadil\%20Sudan.pdf

Oniang'o, R. Allotey, J. \& Malaba, S. J. (2004). Contribution of Indigenous Knowledge and Practices in Food Technology to the Attainment of Food Security in Africa. Journal of Food Science: 69, (3), CRH87-CRH91.

Orindi, V. A. \& Murray, L. A. 2005, Adapting to Climate Change in East Africa: A Strategic Approach. International Institute for Environment and Development (IIED): London.

Osunbitan, J. A. Olushina, J. O. Jeje, J. O. Taiwo, K. A. Faborode, M. O. \& Ajibola, O. O. (2000). Information on micro-enterprises involved in cassava and palm oil processing in the Osun and Ondo states of Nigeria. Technovation: 20, (10), 577-585. http://dx.doi.org/10.1016/S0166-4972(99)00179-0

Parrotta, J. A. \& Agnoletti, M. (2007). Traditional forest knowledge: Challenges and opportunities. Forest Ecology and Management: 249, (1-2), 1-4. http://dx.doi.org/10.1016/j.foreco.2007.05.022

Parry, M. Rosenzweig, C. Iglesias, A. Fischer, G. \& Livermore, M. (1999). Climate Change and World Food Security: A new Assessment. Global Environmental Change: 9, (1), S51-S67. http://dx.doi.org/10.1016/S0959-3780(99)00018-7

Reddy, N. R. \& Pierson, M. D. (1994). Reduction in anti-nutritional and toxic components in plant foods by fermentation. Food Research International: 27, (3), 281-290. http://dx.doi.org/10.1016/0963-9969(94)90096-5

Van de Sande, T. (1997). Socio-economic pitfalls of enhancing indigenous capabilities in household fermentation. $\quad$ Food $\quad$ Control: $\quad 8, \quad 303-310$. http://dx.doi.org/10.1002/(SICI)1099-145X(199703)8:1\%3C17::AID-LDR243\%3E3.0.CO;2-K

Van Dijk, J. A. 1997, Indigenous Soil and Water Conservation by Teras in Eastern Sudan. Land Degradation and Development: 8, (1), 17-26.

Van Hylckama Vlieg, J. E. Veiga, P. Zhang, C. Derrien, M. \& Zhao, L. (2011). Impact of microbial transformation of food on health-from fermented foods to fermentation in the gastro-intestinal tract. Current Opinion in Biotechnology: 22, (2), 211-219. http://dx.doi.org/10.1016/j.copbio.2010.12.004

Yagoub, A. E. Suleiman, A. M. E. \& Abdel-Gadir, W. S. (2009). Effect of fermentation on the Nutritional and Microbiological of Quality of Dough of Different Sorghum Varieties. J. Sc. Tech: 10, (3), 109-119. [Online] Available: http://www.sustech.edu/staff_publications/2010032905492179.pdf 

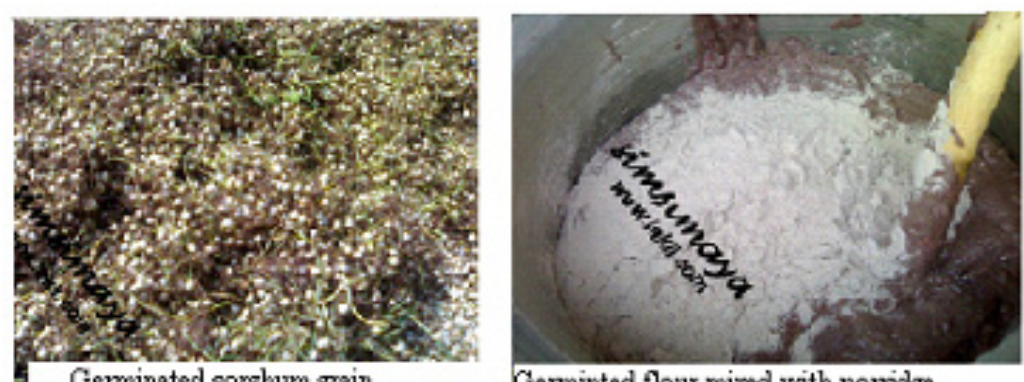

Geminted flour mired with porridge
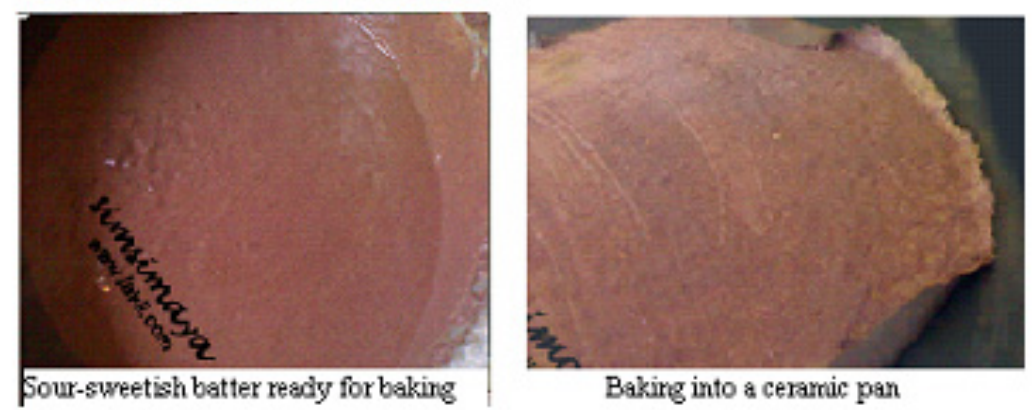

Baking into a cerarric pan

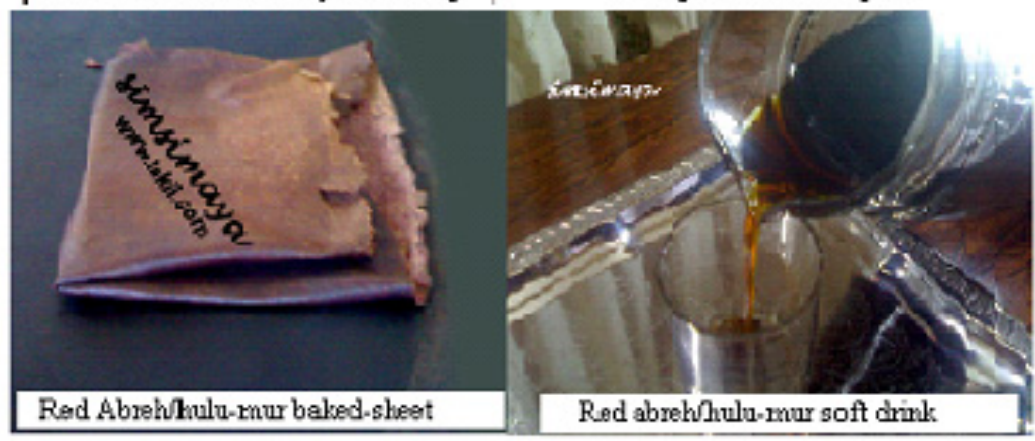

Figure 1. The indigenous technique of making red abreh/hulu-mur

Source of images: http://simsimaya.wordpress.com 

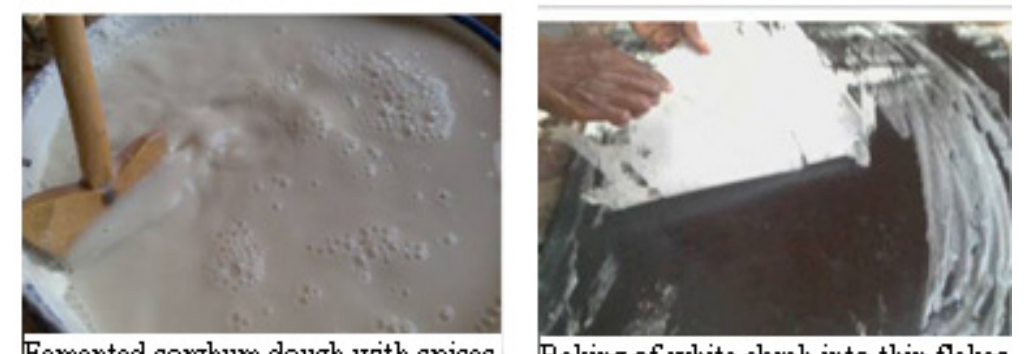

Fermented sorghum dough with spices
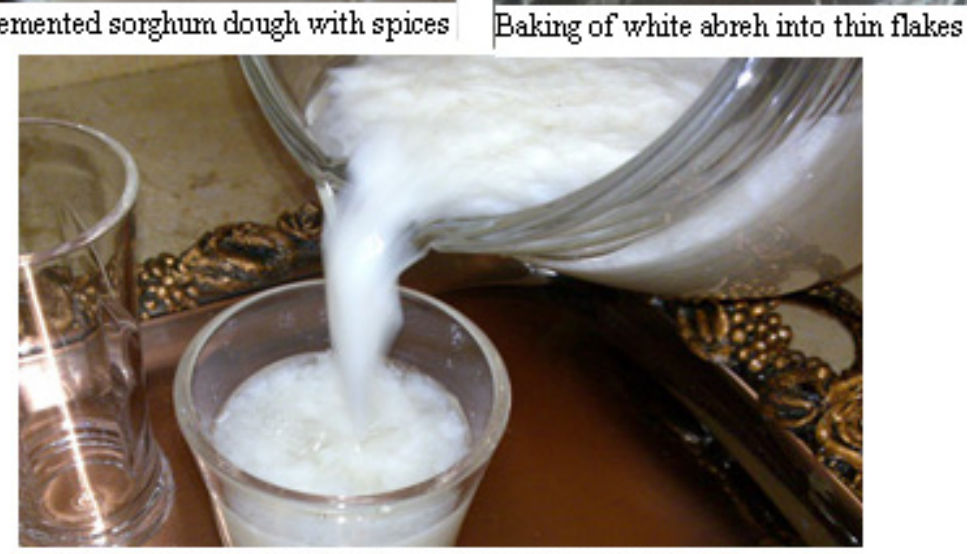

Ready for drinking - cold water and sugar add for taste

Figure 2. The indigenous technique of making white Abreh

Source of images: http://simsimaya.wordpress.com
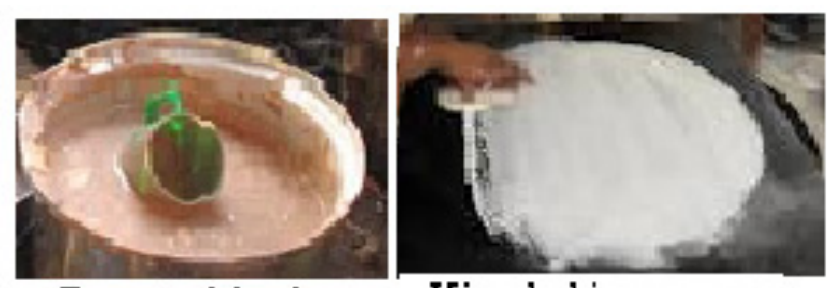

Fermented dough
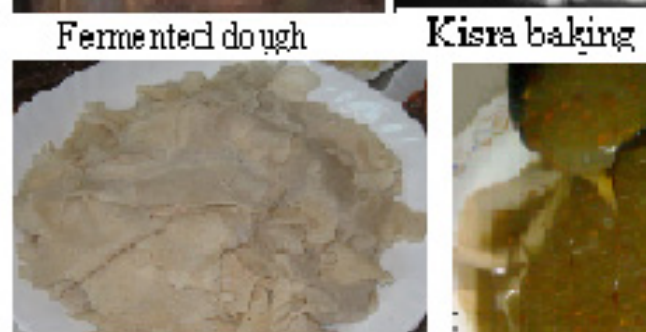

Traditiona flatbread - kisra

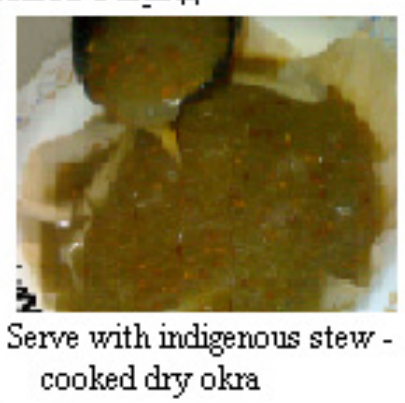

Kisra made of fermented sorghum or millet

Figure 3. Making of kisra (traditional flatbread): Kisra is a type of bread made from fermented sorghum or pearl millet flour 

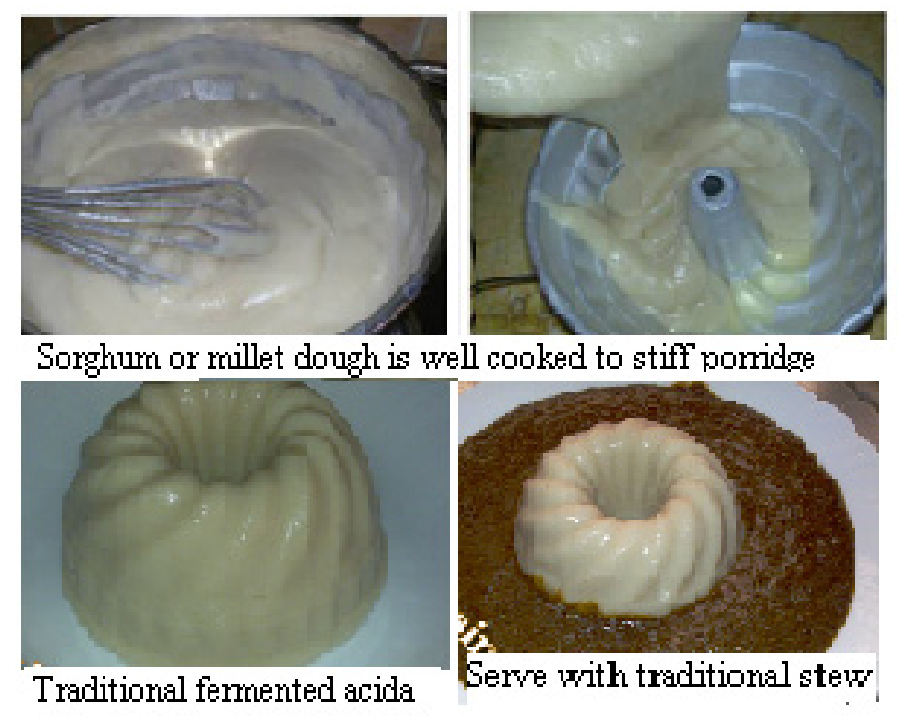

Stiff poridge made of fermented sorghum or millet

Figure 4. Making of acida (stiff porridge): acida is stiff porridge made from fermented sorghum or millet flour Source of images: http://simsimaya.wordpress.com

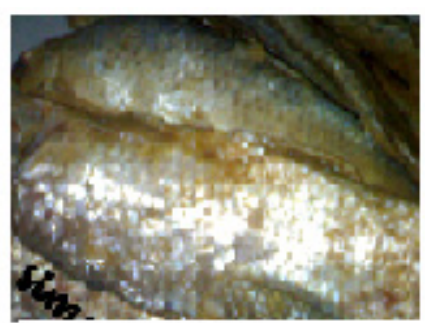

Fe:monted Fieh

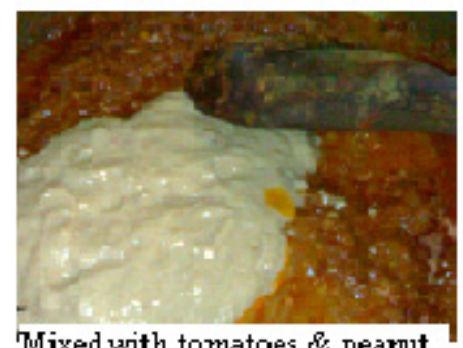

butte $r$ and vegetables

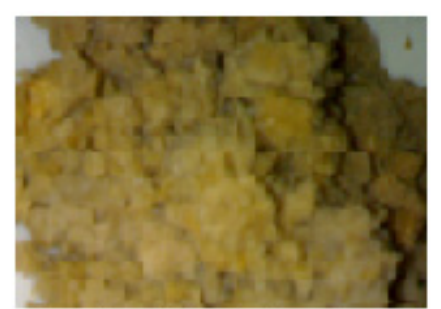

Fessiekh is first minced

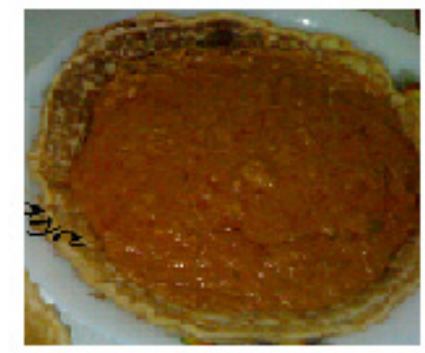

Fessiekh stew serves with groasah

Figure 5. Preparation of traditional fessiekh stew. Fessiekh is a type of wet-salted fermented fishery product Source of images: http://simsimaya.wordpress.com 
Table 1. Amino acids composition (g/100 g protein) and protein content (\%) of hibiscus seed and furundu product

\begin{tabular}{lcc}
\hline Composition & Hibiscus seed & Furundu product \\
\hline Leucine* & 7.99 & 7.73 \\
Isoleucine* & 4.24 & 4.13 \\
Threonine* & 3.34 & 3.42 \\
Methionine* & 1.11 & 0.93 \\
Lysine* & 4.84 & 4.95 \\
Total & $32.28 \mathrm{~b}$ & $33.03 \mathrm{a}$ \\
Protein & $(0.03)$ & $(0.10)$ \\
\hline
\end{tabular}

*Some of essential amino acids.

Adapted from Yagoub \& Mohammed, 2008, p. 354.

Table 2. Analysis of raw and fermented materials in sorghum and pearl millet $(\%$ per $/ 100 \mathrm{~g})$

\begin{tabular}{lccccc}
\hline Item & Moisture & Carbohydrate & Protein & Fat & Crude fiber \\
\hline Sorghum & 6.13 & 74.43 & 12.95 & 3.88 & 1.00 \\
Pearl millet & 6.33 & 70.22 & 13.35 & 6.08 & 1.43 \\
Sorghum kisra & 4.50 & 77.60 & 13.69 & 1.14 & 1.43 \\
Sorghum acida & 4.50 & 47.10 & 15.43 & 1.91 & 1.81 \\
Pearl millet kisra & 5.00 & 72.28 & 15.72 & 3.36 & 1.36 \\
Pearl millet accida 5.80 & 27.73 & 15.46 & 2.43 & 1.27 \\
\hline
\end{tabular}

Adapted from Abdelgadir, et al. 2005, p. 215. 